\title{
6. Philosophy of knowledge perspectives and the study of public administration
}

\author{
INTRODUCTION: METHODS, EPISTEMOLOGY AND \\ LOGICS OF INQUIRY IN PUBLIC ADMINISTRATION
}

PA as an interdisciplinary field of inquiry draws from the social sciences and shares the common problems and quandaries of social scientific knowledge (Homans, 1967; Little, 1991). Importantly, the meaning of the term 'explanation' in the social sciences is always intended to refer both to the understanding of the causes of a given set of phenomena (causation) and the giving of meaning to a social phenomenon (Psillos, 2002; Platts, 1970; Salmon, 1998). Epistemological concerns have been the subject of many works in the PA field, and countless many more in the broader social sciences - it is here treated exclusively from the perspectives of the philosophical foundations, referring the reader to general works on the topic for the field of PA (Riccucci, 2010; van Thiel, 2013).

The specific contribution this book aims to make lies in revisiting logics of inquiry in public administration from the perspective of some broad philosophical themes. We have already indirectly dealt with issues of epistemology in PA throughout the whole book by discussing key philosophical traditions, each having important implications for the philosophy of knowledge: from neo-positivism to post-modernism, from critical realism to phenomenology, from historicism to pragmatism, and so on. We have also already encountered Popper's philosophy of the social sciences and Kuhn's notion of the competition of scientific paradigms and the related distinction between 'normal science', cumulative in nature within a dominant paradigm, and paradigmatic revolutions (see Chapter 3 ). The notion of competing paradigms probably represents the terms in which more often epistemological discussions are framed within the social sciences. However, it has been strongly argued that when it comes to PA, the field is characterised by multiplicity of paradigms, and indeed a babel of paradigms, rather than dominance of one paradigm and knowledge accumulation (Bauer, 2018; Raadschelders, 2005).

There is also a conventional wisdom that three approaches dominate the field: neo-positivism; social constructivism; and critical realism. In line with 
other authors, we argue that this is a limited view and instead a multiplicity of approaches characterise the field, as this chapter indirectly illustrates by reviewing some implications for PA of a much wider range of philosophical streams. A wider range of traditions of inquiry and philosophies of knowledge is indeed detected by a major review of the field: Riccucci (2010) identifies six broad philosophies of science and research approaches in the social sciences that are of significance for PA studies, which the author places under the labels of empiricism, positivism, post-positivism, rationalism, interpretivism and post-modernism/critical theory (Riccucci, 2010, Chapter 4 in particular). In widely reviewing the field of PA, the author identifies and discusses key PA works located in each of these streams (Riccucci, 2010, Chapters 5 and 6). The book ends by arguing for heterogeneity of epistemic traditions being a key trait of the field of PA, and an inexhaustible source of richness to be tapped, not stemmed. ${ }^{1}$

A passage in Riccucci's book is worth noting and recalling here:

The intended purpose of this book is to engage reasonable-minded public administrationists in a dialogue on the importance of heterogeneity in epistemic traditions, and in general to deepen the field's understanding and acceptance of its epistemological scope. The field would be more consonant with the recognition that knowledge is derived from impressions on both the intellect and the senses. (Riccucci, 2010, pp. 2-3)

First, we subscribe to this call for the recognition of the heterogeneity in the traditions of inquiry active in the field of PA, and that the valuing of the contribution each of them can make is a more appropriate stance than engaging in warfare about the alleged superiority of any one of them.

Second, we'd like to pick up on the concluding sentence, where it's stated that 'knowledge is derived from ... both the intellect and the senses'. Taking the very large picture, from a broad philosophical standpoint it might indeed be argued that the multiplicity of approaches to the philosophy of knowledge might be clustered, at a quite lofty, very abstract and rarefied level, into two main intellectual traditions: rationalism and empiricism.

As we have seen, rationalism, in a very basic sense, is the philosophical stance that makes the assumption that ideas are, at least partly, innate, and hence that reason can proceed, at least to some extent, 'on its own' in knowing the world (see, in particular, in our succinct review, the philosophies of Plato, Plotinus, Spinoza, Leibniz and Wolff, in Chapter 2). In this scheme, the opposite camp to rationalism is empiricism, at least where this term is used to refer to approaches assuming that all ideas derive from the senses. ${ }^{2}$ Indeed, it seems that one line of cleavage in PA studies might ultimately lie in where one stands with reference to rationalism and what is entailed by it: the significance of a priori knowledge, mental 'experience', deductive reasoning. Whether these 
are accepted as sources of knowledge proper alongside the knowledge that derives from the senses - or not (in the latter case it is only empirically driven knowledge that is granted the status of 'proper' knowledge) - might constitute a demarcation line between scholarly approaches in the field. Possibly, one implication of properly recognising heterogeneity of epistemic traditions in PA might then be framed as consisting in accepting knowledge contributed by scholars in the rationalism stream as proper and on par with empirically driven knowledge, whilst a way of perpetuating the cleavage might lie in discarding the rationalist strand, on one hand, or in overstating its clout up to shadowing the empiricist strand, on the other hand.

Kant's philosophy is a way of integrating the two perspectives of rationalism and empiricism - although one which quashes key premises of both: differently from rationalism, Kantian philosophy rejects the possibility that a priori ideas are a form of knowledge, as they 'only' represent the preconditions for knowledge to occur: the a priori enables knowledge, but does not contain any knowledge itself (so for Kant the three key ideas of 'self', 'world' and 'God' are purely regulatory ideas): it is only judgements based (also) on experience that may generate knowledge. This assertion is of course contested by rationalists (we have seen in Chapter 3 how critics of Kant turned his system upside down just a few years after his passing away), and thence by rationalists in PA.

However, and very differently to radical empiricism and relativism, the subject of Kant is capable of knowing in a way that is inter-subjective (recognised by all subjects, that is by all human beings, indeed more than that: by all rational beings - though we should specify the term 'inter-subjective' was more systematically used by Hegel), hence rejecting any relativism, other than the very consideration that knowledge is relative to the subject of knowing, the subject - any rational being, any creature endowed with rationality - who is knowing.

In the sense thus specified, Kant's philosophy can be taken as a starting point for a philosophy of knowledge for PA - as said, one that is being challenged in many ways from opposite sides, still a very useful and relevant starting point, because it purports to provide an underpinning to the possibility of knowledge which is universalistic in thrust.

One of these challenges to Kantian philosophy lies in the possibility to know the essences, a claim asserted by the phenomenological movement; for Kant, instead, the essences of things in themselves - the nous - were unknowable, and phenomena were not the door into 'the things in themselves', whilst for phenomenologists they are; it is to phenomenology and its application to PA to which we now turn. 


\section{BETWEEN ONTOLOGY AND EPISTEMOLOGY: PHENOMENOLOGY AND REALIST PHENOMENOLOGY IN PA}

The problem of 'knowing the essences' surfaced both in Chapter 4 when we discussed the 'existentialist public administrator' (it is in fact some form of in-depth knowledge and understanding of things that drives the urge for the 'existentialist public administrator' to 'take responsibility') and in the previous section where we recalled Kant's framing of the problem of the limits of knowledge and the fundamental question of 'what can we know' (also evoked by Geert Bouckaert in his preface to this book). A philosophical movement that programmatically predicated the 'return to the essences' is phenomenology (see the dedicated section in Chapter 3). This philosophical perspective suggests that phenomena, rather than being the limit of knowledge (as in Kant), are conversely the door through which the things in themselves may get to be known by the conscience: in each and every experience, the conscience gets not just a fact, but an essence; knowledge occurs by means of intuition of the essences. Philosophical reflection provides the method for attaining this form of knowledge: it is the bracketing of judgement, known as epoché, that enables things to manifest themselves. In this perspective, phenomenology provides a powerful underpinning for the existentialist public administrator to act, by providing a ground for the judgements she/he makes. This comes with conditions as well: it is only the rigorous application of the method of bracketing of prior judgements that enables the kind of knowledge of essences advocated by phenomenology; knowledge which in turn can underpin making evaluative judgements for decision-making and action.

Within the phenomenological movement there is a substantial division about the foundation of such knowledge of the world. Recalling the distinction between idealist and realist phenomenology (Chapter 3), the key question is whether subjectivity as the phenomenological residue (what cannot be bracketed) constitutes the world in the sense that the world is established by the subject (idealist phenomenology), or whether the world is revealed to and been given meaning by the subject, but somehow the world pre-exists the subject (realist phenomenology). The interpretation of phenomenology more widespread and generally held in PA has been idealist phenomenology; indeed, it has possibly been misinterpreted as the only approach in phenomenology, and then as such upheld, or blamed, for its radical subjectivism. For the same reason it has been the target of the darts of Neo-Positivists, who indicted it for adding a 'morass' that allegedly impedes 'scientific and factual' knowledge, and for its radical subjectivism and hence inherent difficulties in providing criteria for assessing propositions (judgement criterion). 
In our view, already expressed elsewhere (Ferlie and Ongaro, 2015, Chapter 9), the distinction between realist phenomenology and idealist phenomenology would help the debate, and realist phenomenology, as distinct from the idealist variant, could be employed and deployed for a highly valuable contribution to come to grips with foundational issues in the investigation of social systems, allowing for both better 'knowing' and better 'understanding' of them (where understanding is intended as the organising and making sense of what is known, also for practical usages). For example, when we study the processes of strategy formation in a public organisation, we benefit from collecting factual evidence, labelling and measuring it - but this is only part of the picture: we are also dealing with an understanding of what a strategic decision is and what it means for whoever is active in the forming of strategy to make consistent decisions over time capable of shaping the future of the organisation and affecting the professional life of all the people with a stake in that organisation. Realist phenomenology may to this regard provide a more solid foundation for evaluative judgements which, although being given meaning by subjective interpretation (value-laden, normative judgements calling for action), originate in a form of knowledge of the things, of the essences, which is beyond intersubjectivity and is anchored to the object, and hence is in this sense 'objective'. Realist phenomenology may thus be a more solid underpinning for the engaged, caring existentialist public administrator (or publicly engaged citizen), who is then called to 'manage strategically' public services organisations for the bettering of the public services s/he cares for (at least this is our view, already expressed in Ferlie and Ongaro, 2015, Chapter 9).

Summing up, most of the works so far developed in the field of public administration tend to connect phenomenology almost exclusively to social constructivist approaches to the study of public administration (Waugh and Waugh, 2006; Morçöl, 2005), for the very reason that they - implicitly or explicitly - rely mainly if not exclusively on idealist phenomenology, thus ruling out other interpretations that connect phenomenology in its realist variant to critical realism in the social sciences and its applications to the field of public administration. We argue that realist phenomenology might be beneficial for the advancement of the knowledge and understanding of PA.

Moreover, interpretations that connect phenomenology to social constructivist approaches may possibly stretch phenomenology beyond its quarters, when they claim it may provide a foundation for social constructivist approaches to PA. As noticed in Chapter 3, it may be objected that phenomenology is neither 'social' (Husserl placed the absolute subject at the centre, rather than intersubjectivity) nor 'constructed' because in a phenomenological perspective the world may be 'constituted' by the subject (in the idealist perspective), but things can be known in their essence rather than being constructs - although admittedly this is far from unproblematic and is in many respects 
a slippery distinction. A broader and indeed different perspective to the usage of phenomenology in PA, which encompasses its realist strand, may provide, we argue, a fruitful contribution to the field of PA (as well as possibly other fields across the social sciences and the applied professions).

Phenomenology still relies on a strong subject of knowing: the Kantian transcendental subject. This is a main target of public governance scholars rooted in 'relativist' perspectives (e.g. Catlaw and Treisman, 2014). It is to this strand - which constitutes an overall limited, but quite vocal, community in the field of PA - that we now turn.

\section{RELATIVISM AND POST-MODERNISM}

Much of the late 19th- and 20th-century philosophy can also be characterised as a reaction and a critique to the Hegelian system and, with it, of the Kantian transcendental subject. This has led in an important part of the philosophical discourse to the dissolution of the Hegelian system and to a tight querying of the very possibility of grounding ethics and knowledge in the Kantian transcendental subject. Key authors whose work has directly or indirectly contributed to such outcomes include Karl Marx, Friedrich Nietzsche and Sigmund Freud, at times labelled the 'masters of suspicion', questioning whether the strong subject advocated by both Kant and Hegel (albeit in profoundly different terms) actually exists. Instead, it is argued, such strong subject might not really exist but be the product of underlying economic structures determining the form of social classes and their relationships, and the subject in this perspective is in effect only reproducing the system of beliefs of the class to which s/he belongs (Marx); or it may be that the subject is the epitome of psychological processes that underlie and bypass conscience (the psychoanalysis, founded by Freud, ${ }^{3}$ revealed the existence of psychic activity beyond conscience: the subconscious and its influence on psychic processes); or the irrational, Dionysian dimension of the human might constitute the ultimate foundation of human life, leaving little or no room for morality ruling the behaviour of individuals.

Although the contribution to sociological and economic analysis of Marx or the relevance of psychoanalysis as an established discipline are unquestionable, the philosophical implications that have been drawn from the works of these authors have been in their turn subject to close critiques. Whether the existence of subconscious activity is proof of the dissolution of the subject and the impossibility of a transcendental metaphysics, either in the Kantian or in the classical metaphysics sense, is highly questionable; analogously, the influence of economic structures does not necessarily entail a deterministic kind of influence on the totality of the behaviour of the human subject (this critique can be found also in Marxist intellectuals like Gramsci), and the limits of irrationalism (the appeal to Dionysus made by Nietzsche) have also been vetted. In 
sum, it is questionable that either modern (Leibnizian, Kantian and Hegelian) or classical metaphysics can be easily discarded. However, one of the bequests of authors like Marx, Nietzsche or Freud lies in having shaped an important part of the acquired wisdom in the contemporary philosophical debate, where the dissolution of the strong subject as theorised by Hegel and Kant is widely held as common wisdom. Later philosophical movements, like structuralism (Chapter 3), further contributed to the widely held assumption about the dissolution of the rational subject (in the case of structuralism, into underlying social structures), and a vast contribution to this conception was due to a range of French (indeed, Parisian) philosophers; in many respects, also the so-called Frankfurt School contributed to this process (Horkheimer and Adorno, 1979).

This was the breeding ground of the multifarious philosophical strand that goes under the label of post-modernism. The foundation of knowledge and morality in the rational, thinking subject (as in Kant's philosophy) or in the order of things in themselves (as in classical metaphysics) is in this philosophical movement rejected. What remains is 'relativism', both cognitive (which can be summarised in the statement: 'all beliefs are true for their holders') and moral (which relativises righteousness and moral values). It should immediately be noticed that the relativist perspective incessantly opens problems: if any possibility of knowing is ungrounded, and any foundation of what 'ought to be' is deemed to be simply impossible, then what is left is some form of intersubjective agreement, an agreed-upon discourse intended as a patchy aggregate of fragmentary knowledge (oases of knowledge, each with its own only internal justification and 'paradigm') whose traits remain undefined (knowledge is often conceived of as a process) and whose implications remain inherently frail (in terms of what is right and just). We examine this movement, notably its expression in the field of PA, in detail in the remainder of this section.

Before we delve into the works of authors in this stream, an important qualification is in order: works in this school are clearly pluralist in their thrust and engage with a variety of philosophical strands with great mastery. To put them all under a label - that of 'relativism/subjectivism'4 - although capturing some important kind of common thread across the works, is a strained interpretation that may belittle and in a sense caricaturise their wide-scope, often provocative and stimulating, 'thinking-out-of-the-box' contribution to the field. The key authors in this school have made a contribution to a critical appreciation of public administration: they have opened new paths of inquiry by providing a critical and original viewpoint on PA themes. They, however, share common traits in terms of rejecting the rational subject of Kant or the knowability of the world through reason inherent in classical metaphysics. We discuss these traits after having introduced their work. We review, in a necessarily selective way, some of the most significant contributions in this stream. 
A major contribution has been furnished by the works of Box (2005a, 2005b and 2007) and by Fox and Miller, and notably their joint work (Miller and Fox, 2007, which was dedicated to the memory of Fox who passed away in May 2004). Their book provides a very sharp, abrasive at times, critique of representative democracy by challenging the 'orthodoxy' of the majoritarian mode of democracy (pp. 4-5). According to such orthodoxy, the people are assumed to be aware of what they want and need, and choose a representative for elective office by comparing alternative packages offered by competing candidates and parties. In turn, once in office, laws are voted that reflect the people's choice, and a vigilant populace pays enough attention to the governors' choices to be able to judge the elected representatives as either successful or wanting. Finally, the outcome of the subsequent election will be decisively affected by the people's judgement over the incumbent's quality of the job done whilst in office. This is what they refer to as the 'representative democratic accountability feedback loop' or, in short, the loop model of democracy, that the book demolishes - technically: deconstructs - showing its allegedly mythical character. ${ }^{5}$ Three main alternatives are then discussed: the neo-liberal response (which replaces people's will with market mechanisms), the constitutional response (which substitutes the constitution and the effecting of constitutional principles for the electoral victors of the moment), and the communitarian response, or tendency (which 'seeks to replace the loop with direct interface between administration and the citizenry', p. 30).

Miller and Fox's (2007) book then shifts from the pars denstruens (the critique to extant theories or ideologies of representative democracy) to the pars construens, the constructive part of the book, which in this case is primarily a frame for the deconstruction of reality through the notion of media-infused hyper-reality borrowed from communication studies (notably from Baudrillard). The book then works out the social construction of government, mainly patterned on Berger and Luckmann's classical The Social Construction of Reality (1966), although a key inspiration is also Anthony Giddens's theory of structuration, which the authors espouse especially where it aims to 'avoid ascribing to human constructions the immutability that makes institutions seem like granite mountain ranges' (Giddens, 1984, p. 84; however, it may be reckoned that Giddens's work is not social constructivist in thrust and effectively represents an alternative frame, with which the main social constructivist pattern of Fox and Miller's book ends out to be blended). A key passage from Giddens (p. 2, cited in full by Miller and Fox, 2007, p. 84) is that:

One of my principle ambitions in the formulation of structuration theory is to out an end of these empire-building endeavors. The basic domain of study of the social sciences, according to the theory of structuration, is neither the experience of the 
individual actor, nor the existence of any form of societal totality, but social practices ordered across space and time.

It may be noticed that although Giddens's approach is far afield of Hegel's all-embracing (empire-building) thrust, a theory of structuration does not necessarily lead to social constructivism (institutions are created by social action, and yet they may have a relative stability and endurance - 'objective' in its nature - without this entailing them to be conceived of as granite-like: a critical realist research agenda may well encompass among its inspirations Giddens's theory of structuration - see next section).

In Miller and Fox (2007), institutions become conceived of as 'habits', and the authors' analysis of their workings owes much to Michel Foucault's works, notably to the notion of governmentality (Foucault's coin), an instrumental-rationality, disciplinary knowledge-based approach to governing which, according to Foucault, arose in 16th century Europe. What we are left with in our understanding of institutions is the authors' exclusively idiographic accounts (as opposed to nomothetic - on the notion of idiographic and nomothetic, see the illustration of the thinking of Windelband in Chapter 3). The ideograph is the new unit of analysis suggested by Miller and Fox (2007, p. 120):

ideography is the arena of symbolization in which a democratic pluralism of discourse formations become possible. This discursive approach to a hopefully democratic public administration does, we think, imply a way to subtend incommensurability and neotribalism. But within incommensurability is the spark of difference; difference implies the collision of ideographs that can stop the action or redirect it.

Incommensurable, and yet potentially influential and mind-opening, narratives are what we are left with in our attempts to give shape to public governance, according to Miller and Fox.

The authors also very neatly take side in the dispute over the nature of the universals we have dwelt on in Chapter 2: as clearly stated by the authors, 'a constructivist epistemology/ontology is radically nominalist. The names that interactive human groups give things are ultimately arbitrary' (Miller and Fox, 2007, n.p.). A radical nominalism is the position that social constructivist, relativist epistemologies and ontologies should take. This point brings to the fore the actuality of the medieval debate over the nature of the universals: indeed, where we stand in that debate may be very closely linked to where we stand in conceiving of the social sciences in general and of public governance specifically. Realist positions in the conception of the universals appear hardly compatible with radical social constructivism, which tends to be aligned with a nominalist conception of the universals; and it appears the opposite may also hold: nominalist positions in the conception of universals are difficult to 
reconcile with realist positions across the whole gamut (this important point is further discussed later in the chapter).

Farmer $(1995,2005,2010)$ is another key author providing a major contribution to the strand of inquiry in the relativist and social constructivist tradition. His 2005 book is a fascinating, vertiginous tour through re-imagining public administration, ultimately mooring to "post-traditional governance and bureaucracy'. The tour unfolds guided by the works of philosophers, artists and poets through three main themes: thinking as play; justice as seeking; and practice as art. Farmer 2010 is a powerful revisiting of what the author singles out as the five key elements or functions of PA: planning (what does planning mean?); management (what does management mean?); the underlying of PA (values, beliefs, ideologies, symbols and languages); the nature of the field of PA; and the role of imaginative creativity in PA (and one can find here similarities with Weick (1989) on the nature of theory and theory building we recalled in Chapter 3 when discussing alternatives to Popper's epistemology). The rediscovery of these five elements occurs through the perspective of a wide range of disciplines: business and management, economics, political science, critical theories, post-structural theories, psychoanalysis, neuroscience, feminist theories, an ethical perspective and a 'data perspective'.

Probably the most influential work is Farmer's earlier 1995 book. The starting point is the assumption that PA theory and facts are socially constituted and the public administration observer is an image co-creator. The book then challenges established ways of thinking through the analysis of the relationship between language and PA - in other words, through analysing the language of PA. The book eventually moors to proposing a post-modern account of PA, whereby 'play' replaces 'purpose', 'chance' replaces 'design', 'process/performance/happening' replaces 'finished work', 'signifier' replaces 'signified', 'irony' replaces 'metaphysics'(!), 'immanence' replaces 'transcendence' (although one may wonder whether it was necessary to invoke post-modernity to replace transcendence with immanence, given modernity is already about the displacing of transcendence from this world, as so lucidly pointed out by theologians like Dietrich Bonhoeffer). The challenge goes on with 'imagination' that should replace 'rationalisation', and with the upholding of deconstruction, intended as 'a reading that accepts that a sign in the text has no referents' (Farmer, 1995, p. 185; targets of Miller's deconstruction are Simon's grand narrative that equates good PA theory with objectivity, and better theory with more objectivity, p. 187; and that assumes that efficiency is a viable goal for public administration practice), de-territoriality, intended à la Deleuze (the removal of the coding or grid that is imposed on the study of issues or situations), and alterity, referring to the moral other - for Farmer the post-modern is characterised by openness to the other, values diversity, a basic stance of incredulity towards metanarratives, and a radical opposition 
to the established order. Farmer's book represents a fascinating challenge of the constituted order in the study of PA, although at times it seems that it aims at a target that is manufactured to be the straw man, more than representing PA as it is studied and practised. From a methodological standpoint, the reader of Farmer might also wonder whether the logic of radical replacement of allegedly 'old' categories with new ones will ultimately lead to 'better' knowledge, better understanding and better practice of PA. All in all, it appears that post-modernity is in many respects a sort of moral stance, a radical - and radically critical - judgement of previous stances: and we are left wondering what provides the authoritativeness for such stances to topple other approaches from the pedestal of PA.

The work by Abel and Sementelli (2004) provides one of the most systematic elaborations and critical examinations of the - highly problematic - ontological groundings of approaches in the relativist school: it is for this reason that a critical review of their work may provide an example of the significance of spanning across philosophers and philosophies over the ages for a finer grained discussion of the foundations of contemporary public governance and administration. Abel and Sementelli (2004) make a strong claim about the ontological status of a theory of PA: they argue that the 'intersubjective experience of good governance' is the foundation of a theory of PA. Let's vet their argument. Starting with the consideration that administrative theory and practice are concerned with good governance, they argue that

... most agree that what counts as good governance depends upon a 'consensus attitude' toward governmental institutions and actors that is worked out by the citizenry through continued dialogue about competing attitudes, values and beliefs. Hence, good governance is a matter of intersubjective agreement upon how to characterize the experience one has of governmental institutions and actors. This intersubjective experience, though fluid and cognitively less certain than positivist ontology might anticipate, is nevertheless ontologically constituted and therefore the subject of 'first order' theory ... Hence, taking the intersubjective experience of good governance as its subject matter lends ontological status to empirical theory in public administration (it is thus theory) and provides an ontological grounding for normative critique. (Abel and Sementelli, 2004, p. 4)

By leveraging on this assumption, they argue that the apparently unbridgeable theory-practice gap in PA (which according to them neither the Enlightenment hope of applying theory to practice (of enlightening practice through knowledge) nor the Hegelian vision of theory merged to practice (through dialectical synthesis) have been able to overcome) can indeed be filled. The fragmentation in irreconcilable streams and the apparent inapplicability of theories to practice might thus be remedied. The authors aim to overcome the unsatisfactory indeterminacy of post-modernity. They argue that what they call 'evolutionary 
critical theory' (drawing on the work of Thorstein Veblen) may be synergistic across traditional social science, institutionalist and hermeneutical approaches to PA: 'our thesis [is] that public administration synergistically employs the methodologies of traditional social science, institutionalism and hermeneutics by using a reconstructed critical theory as synergistic agent' (p. 160, emphasis in original). This approach allows identifying public administration's subject matter as the intersubjective experience of good governance, and 'since public administration's role is to foster the intersubjective experience of good governance, the discipline is responsible to society and the public as a whole, rather than to some particular political construct such as Congress or the presidency' (p. 9), which the authors argue to provide practical as well as theoretical legitimacy to public administration as a field.

It may be appropriate to dwell on the argument wrought out by Abel and Sementelli in light of a broader philosophical approach to show how the systematic employment of philosophical thought may be beneficial to PA, as a minimum to provide broader perspectives from which to vet the arguments under discussion. First, intersubjectivity is a notion central in the thought of one of the less relativist of philosophers, namely Hegel, whose philosophical system is predicated on the category of necessity of being (Chapter 3). Second, this is combined with a Darwinian argument: 'the theory-practice gap closes, since societies either adapt and change (adopting fitter institutions and processes), or stagnate and die' (Abel and Sementelli, 2004 p. 161); an argument which lies in between the Darwinian 'survival of the fittest' 6 and Hegelian necessity (what that is, necessarily is - see Chapter 3): in other words, the argument the authors put forward may perhaps overcome the frustration encountered by the Enlightenment hope of applying theory to practice when it comes to PA (for which theory appears so estranged), but it may be much closer than the authors reckon to the Hegelian vision of theory merged to practice (p. 11).

Dwelling a bit more on the ontological assumptions: 'we do not experience the world but only have experiences of it' (p. 36 and many other occurrences); a sentence which is prone to some ambiguity, for example when the consequence that 'our cognition cannot be of things in themselves [... and] As the world in itself cannot be confronted, any intersubjective experience of it must be either ontologically given (transcendentally or mundanely) or contingently accomplished by our historical and contextual practices' (p. 41). The authors go on to argue that the idea that intersubjectivity is given transcendentally is ultimately a matter of faith; and that socialisation arguments are not ultimately grounded, thus 'we are returned to the conclusion that intersubjectivity seems an irreducible and non-deducible "datum of everyone's lifeworld". Interestingly, in four pages the authors do away with ontological possibilities discussed over centuries, in most cases without even mentioning them, and ultimately after this brief tour end up relying on Husserl's idealistic phenom- 
enology (plus some indirect reference to the Heidegger of Being and Time) as the philosophical foundation of intersubjectivity: Husserl is evoked to explain how the transcendental 'I' connects with the experience of other 'Is', how the experience of 'the other' enters the consciousness of the individual and constitutes part of the consciousness of the subject. This occurs after having dismissed the Kantian a priori categories of the mind as a leap of faith. This is interesting - even more so given the great intellectual rigour of the authors and the transparency of the flow of their argumentation, which engages with critiques with both total intellectual honesty and great competence. However, the questions remain: in what sense Kant's foundation of the possibility of knowledge in the mind is 'a leap of faith' (p. 44)? Indeed the argument in Kant (see Chapter 3 for a wider discussion) is that in order to have experiences (for example, of change) there has to be something permanent; this is not an object of experience, it is the unifying subject of experience that makes experience possible - in this sense, it is rather the opposite of an act of faith. ${ }^{7}$ Moreover, why is Cartesian foundation through methodological doubt (cogito ergo sum) not even mentioned, given it is the starting point of modern philosophy that seeks in the self the foundation of ontological statements? Why is the perspective of rationalism (that ideas may at least partly be innate) ruled out? For example, the pre-established harmony of Leibniz is exactly an attempt to explain accord amongst the 'experiences' of units (monads in Leibniz's terminology) in the absence of any foundation of intersubjective interactions: why not considering Leibniz's explanation of intersubjectivity ${ }^{8}{ }^{8}$ Here we confined to philosophers and philosophies that share the 'modernist' assumptions about the subject, or self, as the only possible starting point of philosophising (Aristotle has no problems in grounding intersubjectivity in the very knowability of the essence of things by human beings).

It is also interesting to draw some parallels between post-modern authors and the Sophists in ancient Greece. The Sophists conceived of philosophy as a continued critique of the commonly held wisdom, and produced an original body of philosophical thought, which produced ideas that were revolutionary at the time, such as that of the centrality of the subject in knowing and even in setting what is and what is not (Protagoras famously stated that 'man [the human being] is the measure of all things') or put forward radical challenges to human knowledge (like Gorgias's famous statement concerning the unknowability and incommunicability of being ${ }^{9}$ ). Nowadays the word 'Sophist' (usually in lowercase: sophist) carries a pejorative denotation, but this is not appropriate when considering sophism (and the associated giants of philosophy like the mentioned Protagoras and Gorgias) in its proper historical perspective. This philosophical movement ${ }^{10}$ brought with it a powerful humanism as well as a critical, unorthodox for the time, imaginative and creative scepticism towards the then widely held common wisdom. There seem 
to be striking similarities (alongside, it goes without saying, very important dissimilarities) between the poignant critiques to the society of their age made by the Sophists and many positions of contemporary 'post-modern' social constructivists - and this parallel should not be seen in any derogatory sense. If one reads public administration works in this tradition - like Jun (2006), Farmer (2005), Abel and Sementelli (2004), Box (2005a, 2007), Miller and Fox (2007) - can easily spot striking similarities: the praise for imaginative and creative thinking that unveils the hidden side of the functioning of public administration; the emphasis on relativism; the urge to bring about a dialectical bridging of manifold viewpoints as part and parcel of the scholarly work (the call for 'intersubjective agreements' in the absence of a proper knowledgeability of things). These 'calls' may be self-depicted as post-modern, but closely resemble arguments made well over two millennia ago in ancient Greece.

There are, however, also crucial dissimilarities. The ethical stance and thrust of the manifestos of the interpretive, social constructionist approach in public administration is directed towards the building of consensus enough for good governance and an ethical grounding of it (like in Abel and Sementelli, 2004). This is something that was of little concern - if at all - for the Sophists. However, we should not be oblivious of the big contextual differences: the Sophists were not perceived, nor did they see themselves, as a fatal threat to the survival and prosperity of their political community. In ancient Greece, the rift amongst and within city-states (known as 'polis', whose plural is poleis) did not undermine the fundamental political unity both within each city (often with less than 20,000 citizens - the rest being slaves who were void of most rights) and across the whole of the Hellas, that is, the entirety of the Greek poleis, which conceived of themselves as belonging to one common civilisation, the Greek civilisation, even if they were scattered throughout the Mediterranean sea and at times quite far away from the geographical borders of nowadays Greece (Sophists used to wander from one city to the other rather than belonging on a permanent basis to one community). This identity had also been strengthened notably in the face of the Persian menace and the fight for freedom that the Greek people undertook and that is epitomised at the victory of Marathon. By contrast, nowadays complex political systems are made up of millions of citizens, as well as migrants often without citizenship, and they are characterised by multiple cultures or subcultures and are often rife with divisions about the ultimate values. Nowadays political systems are, in a nutshell, hugely more heterogeneous than Ancient Greek city-states or even the whole of Hellas, and hence, for the philosophers of the time, the critique of the mores, the conventions and the widely accepted ways of thinking did not mean acting to undermine the ultimate cohesiveness of the homeland. ${ }^{11}$ Building an ethical community - a community with an accepted ethical grounding and working notion of good governance - was not an issue in the ancient Greece that had 
emerged as victorious in the wars against the Persians, whilst the concern for an ethical foundation and agreed-upon notion of good governance is indeed an issue in contemporary troubled political communities. Stripped of these differences, certain similarities are, however, striking: admittedly the Sophists had a weak vision both of governance and of knowledge - a sort of interpretivist lowest common denominator - and this is not that far from most relativist, post-modern thinking in public governance and administration. Indeed, their stance was very distant from Aristotle's view: and an analogous gulf may probably be found nowadays between social constructivists and critical realists, to whom we now turn.

We have delved at quite some length into the 'post-modern PA' stream of thought, which is quite visible in the field of $\mathrm{PA},{ }^{12}$ whilst other philosophical approaches probably tend to be less vocal and remain under the surface, implicit in the scientific work of scholars in these schools but rarely up front and centre stage in their publications. The most important is probably critical realism, and it is to this that we now turn.

\section{POSITIVISM, NEO- AND POST-}

We introduced positivism in Chapter 3. Positivism purports a primacy of 'scientific knowledge', devoid of any reference to metaphysical knowledge. Scientific knowledge, patterned on the natural sciences, is considered the only accessible form of knowledge, and the method(s) of the natural sciences is generally assumed as pattern for the social sciences as well. In this perspective, the (allegedly) self-evident, incontrovertible 'fact' acquires the status of the only solid foundation of knowledge. This total reliance on scientific knowledge is coupled with a very optimistic view of the benefits that can derive from progresses in such knowledge: a progressive vision of the impact that the accumulation of scientific knowledge may have on humankind and its capacity to overcome the problems that afflict it.

Nowadays we mostly refer to neo-positivism, a powerful revival in the 20th century of the 19th century initial positivism, which addressed some of the more naïve initial claims. A key promoter of this revival was the 'School of Vienna', led by such figures as Moritz Schlick (1882-1936) and Rudolf Carnap (1891-1970). Carnap developed highly influential analyses of the structure of language and his work is associated with the 'logical syntax of language', a systematic statement of the rules that govern a given language and the consequences that follow from those rules, according to the criterion whereby

[a] theory, a rule, a definition, or the like is to be called formal when no reference is made in it either to the meaning of the symbols (for examples, the words) or to the 
sense of the expressions (e.g. the sentences), but simply and solely to the kinds and order of the symbols from which the expressions are constructed. (Carnap, 1937, n.p.)

The language of physics was to express a pattern in this respect. His work aimed at 'purifying' the usage of language for scientific purposes from imprecisions and abuses which in everyday language - and in philosophy - impede the proper formulation of 'verifiable propositions', that is, propositions that express a potential state of fact, whose actuality or not can be verified empirically.

The struggle for a formal language met the challenge of conventionalists, as we have seen (Chapter 3), whilst the procedures for verification - how to verify a proposition - was and continues to be a major methodological problem, as even a very large number of 'verifications' cannot confirm a proposition, whilst just one falsification can decry it (see the critique by Popper of the principle of verification and the proposed replacement with the principle of falsification in Chapter 3). An important part of the second half of Carnap's intellectual career was spent on examining the foundations of inductive logic.

The reason why we have dwelt on this philosopher is - connected to the purposes of this book - for his influence on Herbert Simon, a leading influence in PA and himself an acolyte of Rudolf Carnap and during his formative years in the profession heavily influenced by the neo-positivism of the exponents of the Vienna circle, many of whom had left Europe for the US to flee Nazi persecutions. In the School of Vienna variant, the influence of neo-positivism on Herbert Simon is apparent. Simon entered the PA field in the aftermaths of WWII and his impact has been likened to the explosion of a nuclear bomb (Riccucci, 2010), and the radioactive waste of the burst are still there in PA, although his later research work was mostly carried out in other disciplines, mainly in the fields of organisation science, cognitive psychology, economics (he won the Nobel Prize in economics in 1979), and the philosophy of the design sciences (the so-called 'sciences of the artificial').

The recurrent calls for purification and rigour in language and methods that enable the 'testing' of propositions rigorously controlling for auxiliary assumptions (for an early example, see Perry and Kraemer, 1986) and the rise in influence and impact of journals which put a strong premium on research pieces centred on 'verifiable' propositions (like the Journal of Public Administration Research and Theory) can also be seen as the long wave of that explosion which had led to the lingering influence that neo-positivism has wielded on the field of PA, especially in the US and, more recently and in important respects by means of 'importation' from the US, in countries with large PA communities like South Korea. It can safely be stated that, since Simon, neo-positivism has been an enduring influence in the field of PA (see, 
for example, Rainey, 2001). Notable representative examples - to mention but a few - include many of the works authored by George Boyne, Kenneth Meier, Laurence O'Toole and Stuart Bretschneider.

The lingering influence of positivist attitudes also takes an aesthetic hue, with an emphasis placed in works in this tradition for expressing concepts through mathematical formulas and for elaborating analyses in ways patterned on mathematical modelling.

It is also spoken of a post-positivism, with notable significance in PA (Riccucci, 2010, pp. 84-9). Like all 'post-' philosophies, it retains something but also rejects something else of the philosophy from which it originates. What is retained is the 'objectivity' of the facts somehow lying outside the subject. What is discarded is the almost fetishist allegiance to the 'fact', and the pretension that social sciences can ultimately be patterned on the natural sciences. Post-positivism also stems many of the excesses and overly optimistic claims about the progress of science and its implied utterly positive impact on mankind, or more limitedly and notably for the purposes of this book, any overly optimistic claim about the impact of scientific knowledge on the bettering of public governance and administration. Critical realism has been seen as the most notable manifestation of post-positivism (Riccucci, 2010, p. 84), although, as we have argued, besides representing the 'overcoming' of positivism it may also be interpreted as having roots in other, and older, philosophical approaches, which is why we prefer not to classify critical realism under the label of post-positivism but as a self-standing stream and approach (we discuss critical realism in a subsequent section).

\section{REVISITING THE CONTEMPORARY 'POSITIVISM' VS. 'INTERPRETIVISM' DEBATE FROM A BROADER PHILOSOPHICAL PERSPECTIVE}

The roots of social constructivism/interpretivism may be found in 19th-century philosophical critiques to the strong knowing subject of Kant and the philosophical system of Hegel (Chapter 3), and the critiques of positivism. Nietzsche's assertion that 'there are no facts, but only interpretations' is key to 'weak thought', and thence radical interpretivism, and to the nowadays widespread, up to the point of having asserted itself as common sense, relativism.

However, when seen from the perspective of the history of philosophy, the dichotomy between positivism (however neo- and post-) and interpretivism appears quite narrow, and indeed the interpretation of critical realism as an intermediate point between the two appears quite narrow. New realism (an exponent of which is the contemporary philosopher Maurizio Ferraris) and 'minimal realism' (asserting there exists as a minimum a 'bottom line' reality nobody can 'talk her/his way around', like the immediacy and evidence of 
what basic health or education services provide to the life of every human being) are worthy lines of argumentation, but possibly too shy insofar as they search for an intermediate point between interpretivism and positivism, or to reject their extreme consequences (that reality 'does not exist' other than in the fragmented mirror of each individual, that the 'fact' is the ultimate reality), but entail an acceptance of the basic 'playing field' set up by the interpretivismpositivism dichotomy. Indeed they are but the latest embodiment of a long history of fundamental epistemological reflection that gets well beyond this simplistic dichotomy: the object of intellection - from classical metaphysic (see Aristotle's 'active intellect') to Thomism and neo-Thomism, to Kant's noumenon and neo-Kantism, to Hegel, the notion of object of intellection supersedes both the (in our view misleading) notion of the 'pure fact' and the (in our view equally misleading) notion of the 'subject's interpretation' disjoined from any substantive object of intellection. It is in this line of argumentation that we now turn to critical realism.

\section{CRITICAL REALISM AND ITS FOUNDATIONS: BACK TO THE TRANSCENDENTALS AND ARISTOTLE'S FOUR CAUSES}

Critical realism is an ontological-epistemological approach, whose roots can be found in the works of the philosopher Popper (see Chapter 3), and whose exponents include amongst others Archer (2003), Bhaskar (1975), Hartwig (2007). A contemporary leading exponent is Pawson and, in the field of public administration and management, some of the key proponents are Bouckaert, Pollitt and Talbot (Pawson, 2006; Pawson and Tilley, 1997; Pollitt and Dan, 2011; Talbot, 2005, 2010). Critical realism is grounded in the assumption that reality does not lie entirely in the subject, but it is 'out there' and somehow knowable as such, albeit with major limitations (a line of reflection originally in Xenophanes and then worked out systematically by such philosophers as Aristotle and Thomas Aquinas, see Chapter 2). The knowability of things, of the 'object', as opposed to reality lying exclusively in the subject and the way in which the subject constructs it, is a key tenet of critical realism (the root word for 'real' and 'realism' is the Latin res, which means 'thing'). At the same time, this approach is sensitive to the role the subject performs in knowing, and (also) in this respect it represents a reaction to positivism and neo-positivism, which rather tend to confine the role of the subject to give pre-eminence to the 'fact' (see next section). However, reality is not an exclusive creation of the subject, but rather an objective ontology is centre stage in this perspective, as for example in this passage by Pawson referring to the nature of public programmes and how to analyse them: 'The vital ingredients 
of programme ontology are thus its "generative mechanisms" and its "contiguous context"' (Pawson, 2002).

Pawson, to our knowledge, does not make explicit reference to where he stands in the philosophical 'dispute over the universals' recalled in the previous section when discussing the links between post-modern, relativist stances in PA and a nominalist position in the dispute over the nature of the universals (introduced and discussed in Chapter 2), but it seems quite appropriate to assume that critical realism is more aligned with the realist position in conceiving of the nature of the universals. Also, to continue to refer to theories already debated in the preceding section with reference to relativism and constructivism, it does not appear inappropriate to evoke the theory of structuration put forward by Giddens for a foundation of a critical realist stance.

Finally, although this may be deemed to be a highly contested claim, it may be argued that a critical realist perspective ultimately entails that the categories of being 'are meaningful', either grounded in the rational subject or in the object, that is, in things in themselves. These categories are what classical metaphysics and - with a different twist - Kant referred to as the 'transcendentals'; they are (recalling here the Kantian frame of the categories of being ${ }^{13}$ as outlined in the Critique of Pure Reason - see Chapter 2): Unity, Plurality and Totality (referring to the higher-level category of Quantity); Reality, Negation, Limitation (referring to the higher-level category of Quality); Substance and Accident, Cause and Effect, Reciprocity (referring to the higher-level category of 'Relation'); possibility/impossibility, existence/non-existence, necessity/ contingency (referring to the higher-level category of Modality). It is in fact almost inescapable that if propositions about things have a truth value, they have to rely on the categories of being: of what can be predicated of being, of the possible meanings or significations of being. These categories in turn may be founded (they may ultimately be grounded) either in the rational subject (the Kantian foundation of knowledge) or in the object, in the things in themselves (the foundation of knowledge in classical metaphysics). In sum, it seems there is some form of alignment or, better, continuity between classical metaphysical thinking and critical realism in the social sciences.

Following up on this, we argue further that in this perspective the category of relation, and notably the category of causality in the way it has been originally formulated by Aristotle, namely distinguishing four kinds of causes (see Chapter 2), (re-)becomes centre stage. Our argument is in line with recent calls in the social sciences for the rediscovery of the explanatory framework originally worked out by the philosopher of Stagira (Kurki, 2008; Pollitt, 2012).

These considerations are further discussed in Box 6.1. 


\section{BOX 6.1 THE CONTEMPORARY SIGNIFICANCE OF ARISTOTLE'S FOUR CAUSES FOR PUBLIC ADMINISTRATION AND THE SOCIAL SCIENCES}

Aristotle identifies four types of causes: material, formal, efficient and final (see Chapter 2). The material cause is the material element of which a thing is made. The formal cause is the form or essence of a thing, what gives something the form that makes it be what it is. The efficient cause is what makes change happen, the forces for change. The final cause is the goal or end: the why, what is the reason why something is brought about. Nowadays social sciences tend to treat causality mainly in reference to the efficient cause in Aristotle's terminology, and to subsume the others into this category. For example, the motives or 'reasons why' a social actor is observed to behave according to a certain pattern are intended mainly in the terms of the drivers of a certain behaviour, which in turn produces an observable course of action, which - in conjunction with other 'factors' makes something happen: the final goal or end tends to be placed outside of the scope of the 'observable', or outside the scope of investigation of the social sciences, and hence either disregarded or bent to become part of the 'efficient' cause. ${ }^{14}$ Conversely, Aristotle had a broader view of causation: for him, cause (archè in Greek, which means primarily 'condition' or 'foundation' of something) concerns not just the process whereby something is brought about, but also its ultimate meaning and rationale (final cause, the teleology: why something is brought to being) as well as its inherent essence or form, the what it is of something. Ultimately, the efficient cause is but a part of the explanation of the causes of things. According to an approach informed by an Aristotelian thinking, the formal, material and final causes sit alongside the efficient cause. In order to 'explain' a phenomenon in this broader sense, it is required to attain an understanding of the nature of the object being studied (formal cause) as well as of both the material cause (intended, as we have seen, as enabler, as the potentiality of becoming something: 'matter' here is not intended as the res extensa of Descartes, rather as potentiality in the original sense of the word as used by Aristotle, whereby matter is what enables the process of individuation of universal ideas, is what, literally, makes an individual to be individuated, for example an individual human being to be a concrete individual and not just an image of the idea - in the Platonic sense - of human being), and the final cause, whose systematic adoption means that teleological thinking has a central place in the human-made world. 
This larger array of causes is employed in critical realist accounts: Kurki (2008, pp. 210-34), researching in the field of international relations, argues that Aristotle's typology is highly valuable for the kind of inquiry she sets forth for realistic accounts of social phenomena, and Pollitt (2012, pp. 42-3) revisits the system of the four causes for the field of public management. It is worth dwelling a moment on what these four causes may mean in the field of PA. The analysis of efficient causes is a very sensible starting point: to mention Pollitt's example of a public service, to say that doctors performing an operation in order to save a road accident victim may 'cause' the saving of the patient's life is appropriate, but it is only part of the picture. The prior material existence of a purpose-built operating theatre with suitable equipment, supporting staff and so on is also a cause of the rescue of a life: thus, material and social structures are part of the explanation (material and formal causes). As are the actors' intentions and ultimate goals part and parcel of the explanation: the commitment of clinicians; the civic-ness of passers-by who didn't scurry away but instead called Accident and Emergency to get the ambulance promptly; and, decades before, the decisions by policymakers to establish and develop a national health service. Indeed, Aristotle would probably go beyond the intentions of social actors and add to this the very care for life - its perpetuation and development also inherent in living beings as a final cause. These intentions of social agents in the present moment as well as in a long-gone past that still produces its effects, and the very striving for perpetuating and promoting life by all living beings, which in human beings may also take the form of altruistic behaviours and the care for the anonymous fellowmen, are the final causes that are part and parcel of the explanation of the episode of the saving of a life in jeopardy after a road accident. As another example, the study of Epp et al. (2014) investigating the motives and dynamics of police stops carried out in the US is amenable to being treated according to Aristotle's four causes. Two types of road police stops are considered: traffic safety stops and investigatory stops. The authors found that although in the former category there are no significant differences between socio-ethnical groups, for the latter category blacks have up to three times the probability of being stopped by police for investigation than white people (the study is set in the US). Although this institutionalised practice of investigatory stops may help prevent crimes, it begets a profound sense of discrimination in the black community, with significant impacts in terms of social inequality. There is a statistically significant difference in the perception of being treated fairly by blacks and whites, with impacts on the sense of belonging to the political community, and hence ultimately with profound effects on the way in which citizenship is lived and conceived of. In the terms of the four causes, the effecting of stops by the police is the efficient cause; the machinery 
by means of which this occurs (institutionalised socio-technical practices - thereby including the material resources as well as the legal entitlement by the police to effect stops) is the material cause; the expected and unexpected objectives or 'reasons' being pursued (preventing crime, but also engendering a sentiment of discrimination) is the sphere of the final causes; the very nature of the phenomenon, the exercise of superordinate powers by the government as the monopolist of the use of force in the modern state, is the formal cause.

Asking the reader one more droplet of patience in following this journey into the contemporary significance of Aristotle's thought for PA in particular and the social sciences in general, let's consider another profile of Aristotle's system of causation and the way in which it contrasts with, and may shed light over, contemporary approaches to causation. Let us consider for a moment modern-day Neo-Positivistic approaches favouring statistical methods and ultimately probabilistic causation - a distinction can in fact be drawn between deterministic and probabilistic causality. In deterministic causality, the presence of the cause, alone or in conjunction with others, by itself leads to the effect. ${ }^{15}$ In probabilistic causality, 'the distinction between necessary and sufficient conditions largely tends to disappear' (King et al. 1994, p. 87): claims identify a causal variable and assert that this variable increases the probability of a given outcome; this claim cannot be translated into a claim about the necessary and sufficient conditions for the outcome (in the example reported by King and colleagues, the claim was about poor communication among superpowers during crisis increasing the likelihood of war). These tend to be applied not only to quantitative but also to qualitative phenomena. ${ }^{16}$

How does the very idea of 'probabilistic causation' fit with Aristotle's system of the four causes? It is meat for the teeth of professional philosophers to delve into the problematics of this dimension of Aristotle's thought on episteme and logic. We should add that our question is intended to be provocative, for eliciting reflections that may shed light on contemporary approaches in the social sciences rather than for anachronistic comparisons (the hindsight of centuries of philosophical thought and the dramatic changes brought about by the 'modern' sciences and contemporary social scientific inquiry make this exercise just this: a provocative reflection). However, this mental exercise may shed light on unexpected parallels with contemporary debates. It is doubtful the Greek philosopher would content himself with the search of some sort of correlations as an adequate explanation for 'the causes of things'. Indeed, Aristotle had a very different approach from both Sophists' scepticism about the possibilities of human knowledge and from a conception of causation as the search for some sort of 'correlation' detached from 'explanation' of the underlying causal mechanisms. ${ }^{17}$ 
Searching in an integrated way for the essence of things (the formal cause), as well as the teleology of things (the final cause), and not least for a rational understanding of the agent of change (the efficient cause), is a different research agenda from either of the two previously mentioned approaches. Aristotle did not content himself with 'weak' thought and patchy and fragmentary knowledge. In this respect, it does not appear too far of a stretch to consider that the fundamental thrust of contemporary realists and critical realists (à la Pawson and Tilley, 1997; Kurki, 2008 - and Christopher Pollitt or Geert Bouckaert in the field of PA) bears resemblances with Aristotle's fundamental thrust, and the contentions contemporary critical realists have with (especially) radical social constructivists displays close parallels with the contentions Aristotle, and Plato before him, had with the Sophists.

\section{THE CONTEMPORARY MEANING OF THE DISPUTE OVER THE UNIVERSALS}

In Chapter 2 we already noted the enduring significance of the nature of universal concepts, a debate which concerns the issue of whether universal concepts are real and exist as (ideal) objects, or are real and the product of a procession of abstraction by reason, but only individuals are real in the proper sense, or are not real at all.

What are, then, deliberately engineered social systems for the running of a public organisation, like a strategic planning system, a management accounting and control system, a human resources management system, a total quality management system, and the like? Are they the same thing anywhere in the world (and any time), just intermingled with haphazard elements that blur the pure nature of the ideal object? This position may appear implicit in quite a number of pieces of scholarly inquiry: public management and administrative systems tend to be treated as 'objects' (of thought) virtually tantamount across contingencies, although performing differently or displaying different features depending on the circumstances.

Or are a strategic planning system, a management accounting and control system, a human resources management system, a total quality management system, and the like a mere flatus vocis, utterance of the voice: whoever talks or writes about such systems utters the same sounds or scribes the same graphical picture (if s/he is talking or producing a written piece in the same English language which nowadays is the lingua franca, vehicle language), but in the mind of each individual beholder different things are meant by the same sound or script. This has been stated quite explicitly by a number of scholars, notably 
in the post-modernist school (Farmer, 2005; Abel and Sementelli, 2004; Miller and Fox, 2007).

But is it the whole story, or does a strategic planning system, a management accounting and control system, a human resources management system, a total quality management system, and the like mean (signify) something more? A moderate realist/critical realist would argue that what exists are individual strategic planning systems, human resources management systems, total quality management systems, and the like, but reason can distinguish, separate and, in a sense, abstract the characteristics that qualify and are in common to all these individual things belonging to the same genus or category (or class or set, to use modern logic terminology).

As discussed earlier (see in particular the section on post-modernism and relativism), the actuality of the medieval debate over the nature of the universals is witnessed by the observation that where we stand in that debate may be very closely linked to where we stand in conceiving of the social sciences in general and of public governance specifically. Importantly, it may be claimed that in multiple respects where a PA scholar stands in terms of her/his conception of the nature of the field of PA depends on her/his philosophical stance over the nature of universal concepts. This dispute is in many respects still raging nowadays. ${ }^{18}$

\section{NOTES}

1. An argument that assumes and most welcomes, but in a sense goes beyond, the call for methodological pluralism, arguing for plurality of philosophies of inquiry lying at the heart of the field.

2. One notably radical empiricist position is that of the philosopher David Hume (see Chapter 2). Hume has been an influential figure for the social sciences, and one important concept he has introduced in the scholarly debate is the notion of beliefs formation, which is so central to contemporary cognitive and social psychology, and it is widely applied across the social sciences; the notion of beliefs formation makes an important contribution to the field of PA via representing a conceptual tool for theories of policy learning, on one hand (Dunlop and Radaelli, 2018) and behavioural PA, on the other hand (Grimmelikhuijsen et al., 2017; Olsen et al., 2018).

3. Based on intuitions of philosophers like Leibniz, who first noticed how there is a wider range of perceptions than those that receive the attention of our vigilant conscience and that all impact on our psychic activity.

4. A clarification is required about the notions of 'relativism' and 'subjectivism', which are used in this section to refer to post-modernism (and in a later section to refer to one perspective in phenomenology applied to PA). The point is clearly made by Raadschelders (2005, pp. 622-3) and we borrow definitions from him: 'relativism as used in this article includes both cognitive (i.e., all beliefs are true for their holders) and moral relativism (which relativizes rightness and moral values). While I use the concepts of subjectivism and relativism as related, they 
are distinct concepts. The relativist observation that there are no "correct" answers is not subjectivist, for it does not refer to a particular time and context. The subjectivist observation that soft drugs ought to be legalized is not relativist, for it is an opinion that can find support with some and resistance among others in one time and context (i.e., country). Postmodernism has both subjectivist and relativist features.'

5. The critique of the democratic loop is a topic widely debated in political science (recently Achen and Bartels, 2016), although much less often with a focus on drawing implications for the theory and practice of PA, as Fox and Miller set out to do.

6. Darwin only introduced the notion of 'survival of the fittest' in the fifth edition of On the Origin of the Species, and generally left the answer quite open to the issue of what determines certain genetic mutations to thrive and reproduce.

7. Hegel went much farther in cutting the knot by postulating the creative activity of the mind occurring on a cosmic scale rather than at the level of individual consciousness, and hence our possibility for knowledge is indeed the result of reason having created the world, and Reason (in capital) created the world for the very reason that Reason itself is an episode in the life of the all-embracing Spirit.

8. Similarly, it appears as a minimum overstated the claim $(2004$, p. 171) that 'Eaton [e.g. 1923 - our note] arguably made one of the first reasonable efforts to examine knowledge outside of the teleological boundaries created by being a critical realist, neorealist, or idealist ... particularly if we consider that knowledge might be a knowledge of appearances, not realities themselves (!). In addition, he argues that truth is based on agreement (!)' (our exclamation marks): we are struck by invoking Eaton (not the most known of philosophers) for a decisive solution to millennia-old debates: the argument that 'knowledge might be knowledge of appearances, not realities' is nothing new (what's the difference between this claim and the sceptical philosophy of the Hellenistic period? And isn't Kantian categorisation a reaction to Hume's radical empiricisms, exactly to limit knowledge to phenomena (the absolute in Kant can be gained by human beings only through the adherence to moral tenets and the aesthetic experience of sublime)? And for Hegel realities are in the mind exactly because he (claims to) overcome the Kantian notion of 'noumena', of the things in themselves as the unknown. And as regards the claim that 'truth is based on agreement', Sophists were arguing in a similar vein over two millennia ago - indeed they also drew some self-interested implications and asked for compensation for teaching the sons of the wealthy how to argue effectively to convince the multitudes to agree on what is convenient for themselves - a good reminder of the dangers of rejecting any criterion of truth. In sum, providing an ontological grounding to constructivist approaches to PA (and beyond) is a very problematic task, and a task that has not yet been accomplished (if ever it will be - something we strongly doubt).

9. Indeed, Gorgias even stated that 'nothing is', arguing that either the being is, or the non-being is, or both the being and the non-being are: but the non-being is not - by definition - whilst the being either is eternal or generated, or both. If it's eternal, it's infinite, but the infinite is in no place, and hence it is not. If it's generated, either it's been generated by the non-being or by the being; but the non-being cannot generate anything, and the being, if it is being, should already be and hence only nothingness is - indeed an example of a Sophistic argument.

10. Not to be confused with the - linked - subsequent philosophical movement of the scepticism that thrived during the Hellenistic period. 
11. Admittedly this is mostly a notion produced by later epochs - like the patrie of the French revolution - albeit a strong sense of a common civilisation is generally considered to be a defining feature of ancient Greece.

12. We have discussed the works of Fox and Miller, Farmer, and Abel and Sementelli because they are highly representative of this stream of thought, but it should be noted there are many other important works in this strand, to which we cannot do justice for reasons of brevity.

13. Aristotle, who first fully theorised the 'categories of being', identified the following ones: substance; quality; quantity; relationship; acting or action; 'passion' (in the - etymological - sense of being subjected to something, of receiving the effect of an action as opposed to acting); place; time. These are the main categories; Aristotle also additionally mentioned 'having' and 'lying', but these are seldom used elsewhere by Aristotle, and reference is usually made to the first eight.

14. One standard social science definition of 'causal effect' is as 'the difference between the systematic component of observations made when the explanatory variable takes one value and the systematic component of comparable observations when the explanatory variable takes on another value' (King et al., 1994, pp. 81-2). In King et al.'s approach, the explanatory variables are referred to as the 'causal variables' (revealingly also called the 'treatment variables': their status hinges upon the manipulator rather than enjoying the status of cause by themselves) and are distinguished from the control variables. This definition is close to the notion of efficient cause in Aristotle's framework, whilst the other causes, and notably both the final cause and the formal cause, tend to disappear from the horizon of the investigator.

15. It is further distinguished between necessary and sufficient conditions: a necessary condition, or cause, must be present for the effect to manifest itself, but by itself is not enough and other conditions must be present as well; a sufficient condition means that its presence by itself determines the ensuing of the effect.

16. This is the core argument of King et al. (1994, p. 87). We also recall here the definition of 'causal effect' put forward by King et al. as 'the difference between the systematic component of observations made when the explanatory variable takes one value and the systematic component of comparable observations when the explanatory variable takes on another value' (King et al., 1994, pp. 81-2).

17. It goes without saying, many research works resorting to the notion of probabilistic causation do attempt to provide explanations for the social phenomena and do not limit themselves to asserting a probabilistic link - the reference here is to those that refrain from such attempts and content themselves with having established some sort of correlation.

18. Bhaskar (1975), a leading scholar in realism, and Elder-Vass (2010, pp. 44-7 in particular) develop a similar line of argumentation and, in our view, they address the same issue outlined by the dispute over the nature of universals albeit with a different terminology, thence reinforcing our claim about the vivid actuality of this issue. 